\title{
BMJ Open Mixed methods study exploring parent engagement in child health research in British Columbia
}

\author{
Jennifer Smith, ${ }^{1}$ Ian Pike, ${ }^{1,2,3}$ Mariana Brussoni, ${ }^{1,3,4}$ Lori Tucker, ${ }^{2,3,5}$ Louise Mâsse, ${ }^{3,4}$ \\ Janet W T Mah, ${ }^{3,5,6}$ Ainsley Boudreau, ${ }^{5}$ Dawn Mount, ${ }^{3}$ Russell Bonaguro, ${ }^{3}$ \\ Stephanie Glegg, ${ }^{7}$ S Amed ${ }^{2,3,5}$
}

To cite: Smith J, Pike I, Brussoni M, et al. Mixed methods study exploring parent engagement in child health research in British Columbia. BMJ Open 2019;9:e025404. doi:10.1136 bmjopen-2018-025404

- Prepublication history and additional material for this paper are available online. To view these files, please visit the journal online (http://dx.doi. org/10.1136/bmjopen-2018025404).

Received 16 July 2018 Revised 16 February 2019 Accepted 17 April 2019
Check for updates

\section{(C) Author(s) (or their} employer(s)) 2019. Re-use permitted under CC BY-NC. No commercial re-use. See rights and permissions. Published by BMJ.

For numbered affiliations see end of article.

Correspondence to

DrS Amed; samed@cw.bc.ca

\section{ABSTRACT}

Objectives The objective of this study was to explore parent perspectives of and interest in an interactive knowledge translation platform called Child-Sized KT that proposes to catalyse the collaboration of patients, families, practitioners and researchers in patient-oriented research at British Columbia Children's Hospital (BCCH).

Methods An explanatory sequential mixed methods design was used over 1 year. Over 500 parents across BC completed an online survey, including a subsample of 102 parents who had accessed care at BCCH within the past 2 years. The survey explored parent perspectives about the value of their engagement at all stages of the research process and their interest in and concerns with using an online platform. Following the online survey, two focus groups were held with parents in the Vancouver area to explore themes emerging from the survey.

Results Parents expressed keen interest in engaging in research at $\mathrm{BCCH}$. Parents perceived benefit from their input at all stages of the research process; however, they were most interested in helping to identify the problem, develop the research question and share the results. Although parents preferred online participation, they had concerns about protecting the privacy of their child's information.

Conclusions Parents see value in their involvement in all stages of child health research at $\mathrm{BCCH}$. Their input suggests that Child-Sized KT, a hypothetical online platform, would facilitate meaningful stakeholder engagement in child health research, but should offer a customised experience and ensure the highest standard of data privacy and protection.

\section{INTRODUCTION}

Patient-oriented research engages patients as partners to ensure that the research addresses patient-identified priorities to improve patient outcomes. ${ }^{1}$ For engagement to be meaningful and productive, researchers must avoid insincere involvement of patients or their representatives, and utilise a model that supports constructive collaborations throughout the research trajectory. ${ }^{2}$ For example, ensuring that representation of patient partners on the

\section{Strengths and limitations of this study}

- This study is the first to describe the process of collaboratively developing a platform to support bidirectional knowledge exchange between researchers and paediatric stakeholders.

- A strength of our study was the exploratory sequential mixed methods design, which allowed for rich data to be generated via qualitative exploration of themes emerging from quantitative data.

- The sample of focus group participants was limited by budgetary constraints, and the sample of parents from British Columbia Children's Hospital was confined to a single clinic because of limited resources and timelines.

team is sufficiently diverse, that patients are appropriately supported with financial or other needed resources, and that patient partners feel accepted as equal team members, are all ways to encourage meaningful participation. ${ }^{2}$ Engagement platforms, such as advisory groups, steering committees, consumer panels and Cochrane review groups, have allowed researchers to source important research questions, identify relevant cultural issues, improve study protocols and optimise study recruitment, among other benefits. ${ }^{3}$ Meaningful engagement of parents and caregivers is particularly important when it relates to the care and involvement of children in health-related research as parents can give voice to their children's needs and perspective. There is a paucity of research on how to meaningfully engage parents and caregivers in the research process; however, a recent scoping review suggests their involvement has been shown to improve the relevance, quality, credibility and uptake of research results. ${ }^{4}$

To address this need under the Canadian Institutes of Health Research Strategy 
for Patient-Oriented Research (CIHR SPOR) initiative, researchers at British Columbia Children's Hospital (BCCH) undertook a project to expand beyond conventional forms of patient engagement (ie, as research participants) and engage parents and caregivers as true partners in research. ${ }^{5}$ As the leading paediatric care facility and research institute in $\mathrm{BC}$, we envisioned a sustainable platform at BCCH for stakeholders-paediatric patients and their families, practitioners and researchers-to work together to address important issues related to child health. The proposed platform, called 'Child-Sized KT', is intended to accelerate progress towards achieving the CIHR SPOR vision of patients as active partners in health research by providing the means to catalyse collaborative discovery, improve child health outcomes and enhance child health services in $\mathrm{BC}$ and beyond.

Paediatric disease-specific research networks already exist and their efforts have expedited the translation of evidence into practice. ${ }^{6} 7$ However, no published literature describes the process of collaboratively developing a platform to support bidirectional exchange between researchers and paediatric stakeholders. Consistent with recommendations regarding person-based approaches to intervention development, we undertook this study as a first step towards developing Child-Sized KT. ${ }^{8}$ The objectives of this study were, therefore, to understand parent perspectives on (1) participating in child health research, (2) the type of platform that would best facilitate engagement, as well as (3) barriers and facilitators to engaging in research at any stage of the process. The findings of this study will be used to develop a Child-Sized KT prototype designed to respond to stakeholder-identified needs and priorities.

\section{METHODS}

\section{Study design}

A mixed methods explanatory sequential study design was used. $^{9}$ A quantitative province-wide survey was followed by two qualitative focus groups to explore and explain the results of the survey data. A sequential explanatory mixed method study design that uses a quantitative survey component followed by qualitative focus groups to corroborate the findings provides a more in-depth exploration of identified relationships and has been used in previously published health research. ${ }^{10-12}$

\section{Participants}

The target population was parents across the province of BC with children under 18 years of age living in their household. Parents were recruited via Insights West, a full-service market research company that maintains a survey panel of adult volunteers in Western Canada (https://insightswest.com). All potentially eligible panel members were sent an invitation to participate and a survey link by email. Panellists were eligible to participate if they had a least one child living at home and took a role in medical decision-making on behalf of that child.
Parents of healthy children were eligible, as were parents of children who had accessed care at BCCH in the past. To ensure some representation of parents who were familiar with $\mathrm{BCCH}$, the survey link was also sent to all parents of children who had accessed care through the diabetes clinic within the past 2 years. The population of parents from the diabetes clinic was chosen for convenience, as it is one of a few clinics at BCCH that collects parents' email addresses, and was readily accessible. Quotas for each sample were based on the maximum number of respondents that could be accommodated within the study budget. Reminder notifications were sent to provincial panellists, but no follow-up emails were sent to BCCH parents.

Survey respondents had the opportunity to identify whether they would be interested in participating in a focus group held at the Insights West facility. Focus group participants were purposefully sampled for maximum variation based on their demographic characteristics and survey responses so that each would bring a unique perspective, thereby maximising demographic and experiential heterogeneity within the group. ${ }^{13}$

\section{Patient and public involvement}

Parent stakeholders were not involved in the design, implementation or interpretation of the present study, as one of the primary objectives of this study was to gauge whether or not parents would be interested in the first place. Subsequent phases of the project (ie, prototype development) will involve parent partners as members of the research team. The focus group guide was developed out of parents' priorities, preferences and experiences identified by the survey data.

\section{Measure}

In addition to collecting demographic information, the survey items measured awareness of ongoing research at $\mathrm{BCCH}$, positive and negative experiences related to participation in health research, as well as interest and willingness to engage in research (Appendix A). The survey also asked parents about motivators and barriers to participation, how they would like to be engaged, what stages of the research process they see benefitting most from their input, as well as the functionality and features of the hypothetical Child-Sized KT platform that would best serve their needs. Participants were shown a diagram of the research process (figure 1) and given a definition of 'participation in research' as engagement at any or all stages of the process. Participants were instructed to consider this definition as they completed the survey.

A focus group guide was developed based on preliminary analysis of the survey and explored emerging findings related to information sharing, privacy, functionality of the hypothetical platform and the factors underlying parent engagement at each stage of the research process. The focus groups were held at Insights West, facilitated by a professional facilitator, and were audio-recorded and video-recorded. 


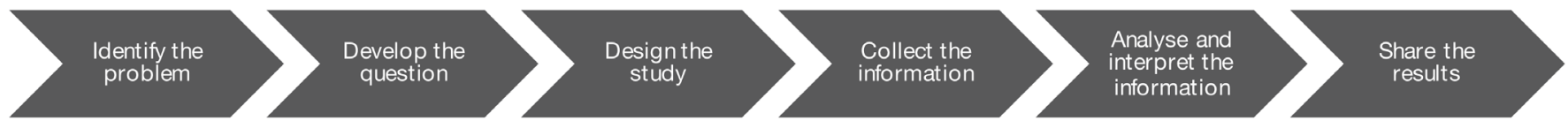

Figure 1 The research process.

\section{Analyses}

Survey data were analysed using SPSS V.24.0. Responses from panellists were described separately from diabetes clinic respondents, as recent experience at the hospital may have an influence on the pattern of responses from the BCCH parent sample. Frequencies were calculated to describe the distribution of parent responses within each sample. A conventional approach to content analysis ${ }^{14}$ was used to organise and code the data according to the study objectives that were developed by the research team and informed by the quantitative survey results (Appendix B). The Insights West team coded the field notes, referred to the audio and video recordings to clarify the meaning, and flagged quotes that illustrated each theme they identified. Lastly, the BCCH research and Insights West teams reviewed the data together to discuss alternative themes and interpretations until all inconsistencies were resolved. This process of triangulation examined the survey data to cross-check themes that emerged from the focus group data, providing a more detailed and balanced analysis. ${ }^{13}$

\section{RESULTS \\ Survey}

A total of 421 parents from across $\mathrm{BC}$ and recruited via the Insights West panel completed the survey with an additional 102 responses from parents who were directly recruited via the $\mathrm{BCCH}$ diabetes clinic. Response rate from the Insights West panel was $81.8 \%$. Survey links were sent to 1173 parents seen in the diabetes clinic; the survey closed after the quotas of approximately 400 completed surveys from the provincial panel and 100 completed surveys from BCCH parents were reached. Once the survey closed, no further responses could be submitted.

Demographic characteristics are presented in table 1. The distribution of respondents throughout the province was approximately representative of the proportion of the population residing in each of the five health authority regions. ${ }^{1516}$

Overall, parents ( $\mathrm{n}=388 ; 74.6 \%$; $95 \%$ CI 70.9 to 78.4$)$ were aware that research is conducted at $\mathrm{BCCH}$ and were interested in supporting research. They were motivated to positively impact their own child's health, as well as the health of other children (figure 2). However, only $17.0 \%$ ( $\mathrm{n}=89 ; 95 \%$ CI 13.8 to 20.2) of parents surveyed had actually participated in a study. Of those who had participated in a study, many reported positive or very positive experiences $(\mathrm{n}=85 ; 95.5 \%$; $95 \%$ CI 91.2 to 99.8$)$. Parents were most often involved in data collection $(n=69$ of $87 ; 79.3 \%$; 95\% CI 68.9 to 86.2 ) and/or identifying the problem $(\mathrm{n}=25$ of $87 ; 28.7 \% ; 95 \%$ CI 19.2 to 38.2$)$. Very few were involved in developing the research question $(\mathrm{n}=13$ of $87 ; 14.9 \%$; $95 \%$ CI 7.5 to 22.4 ), designing the study $(\mathrm{n}=8$ of $87 ; 9.2 \%$; $95 \%$ CI 3.1 to 15.3$)$, analysing or interpreting the data $(\mathrm{n}=14$ of $87 ; 16.1 \%$; $95 \%$ CI 8.4 to 23.8$)$ or sharing the results $(\mathrm{n}=13$ of $87 ; 14.9 \% ; 95 \%$ CI 7.5 to 22.4 ). When asked which stages would benefit most from their input, parents perceived benefit at every stage (figure 3); however, parents perceived the most benefit in identifying the problem and the least benefit in analysing and interpreting the data. More BCCH parents perceived benefit in developing the research question than did the BC panel.

The greatest barriers to engaging in the research were time commitment and travelling to the hospital (figure 4). The majority of parents $(n=435$ of 490 ; $88.8 \%$; $95 \%$ CI 86.0 to 91.6 ) expressed a preference for online participation. Parents indicated that they would use an online platform to find information about research at $\mathrm{BCCH}$, although some were concerned about privacy. Some wanted to be able to see all opportunities for engagement in research and choose those that are of interest ( $n=263 ; 50.3 \%$; $95 \%$ CI 46.0 to 54.6), while others only wanted to be notified about those that are relevant to their child's health condition $(n=227$; $43.4 \%$; $95 \%$ CI 39.2 to 47.7 ).

Stages of the research process in which parents said they were most likely to engage were identifying the problem, developing the question, collecting the data, and sharing the results. Parents expressed somewhat less interest or confidence in designing studies, data analysis or interpretation (figure 5).

\section{Focus groups}

Between two focus groups, six men and nine women participated. Parents came from a variety of cultural and socioeconomic backgrounds, with a wide range of experiences related to paediatric health issues. Themes that emerged and were explored during the focus groups included parents' perceptions of, and interest in, contributing to each stage of the research process; the usefulness of an online platform for facilitating meaningful discussions; and concerns about privacy, research ethics, 
Table 1 Survey respondent characteristics

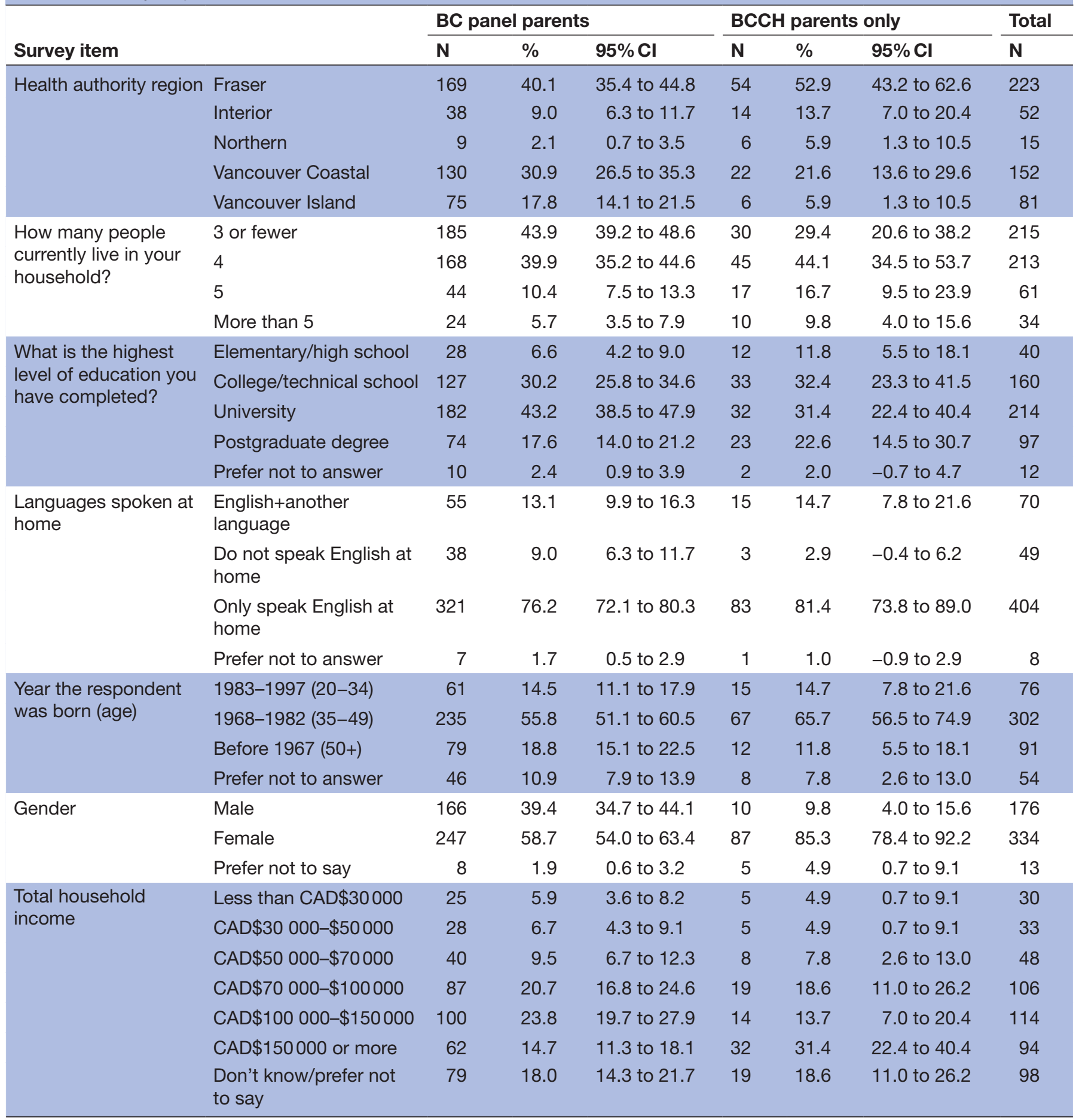

BC, British Columbia; BCCH, BC Children's Hospital.

accountability and understanding the standards to which researchers are held.

\section{Contributing to the research process}

Parents in the focus groups expressed interest in engaging as members of the research team because they felt involvement would ensure the study outcomes would be relevant and useful for patients and families: 'With [parents] living the experience, professionals might not even know the questions that we [parents] are grappling with'. They felt that their contributions would guide researchers towards the heart of the problem and forge a path towards meaningful results: 'helping design the question, which may help to get an answer that might be useful. Parents felt less confident or interested in contributing to data analysis and interpretation, because they perceived a need at this stage for a specialised skill set in order to meaningfully contribute. 
Doing something that may have a positive impact on my child's health

Working on an issue that is important to me and/or my child

Being able to help others

Being able to find out the outcome of the study

Knowing how the findings are being used in the hospital

Being able to be heard by healthcare professionals

Being paid for your time

Remaining anonymous throughout the research process

Being able to work with my medical team who I'm familiar with

- A great deal (BC panel parents)

- A moderate amount (BCCH parents only)

0

How much would the following factors motivate you to participate in a research project?
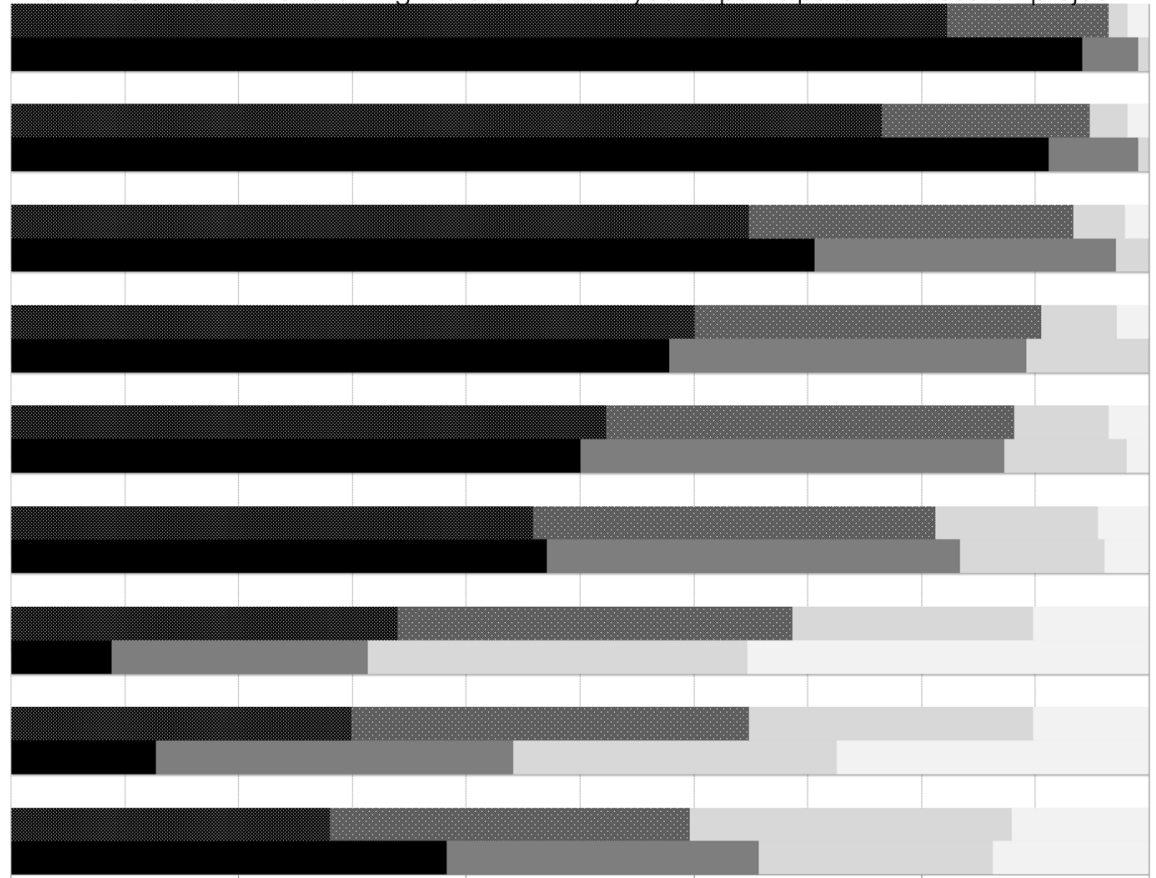

0.2

0.6

0.8

Proportion of sample

- A great deal (BCCH parents only)

A small amount (both samples)

Figure 2 Motivators. BC, British Columbia; BCCH, BC Children's Hospital.

Lastly, parents saw a significant role for themselves in disseminating results, both for their own benefit and the benefit of others, as 'being in the know' was an empowered state from which they could affect change. Selected parent quotes are shown in figure 6.

Communicating through an online platform

Focus group participants discussed Child-Sized KT as an online platform: how it might be used, as well as perceived barriers or other concerns. Parents felt a platform that facilitates conversation between themselves, healthcare professionals and researchers would be of interest, but expressed little to no interest in an open discussion forum, as they said that this feature would present an opportunity for the proliferation and spread of misinformation and negative comments by 'trolls'. Parents said that they would likely spend too much time sorting through ' a lot of garbage' to find any information of value. However, a communication platform with a specific purpose, trustworthy content, vetted membership, and that is actively monitored by a professional, was considered more desirable.

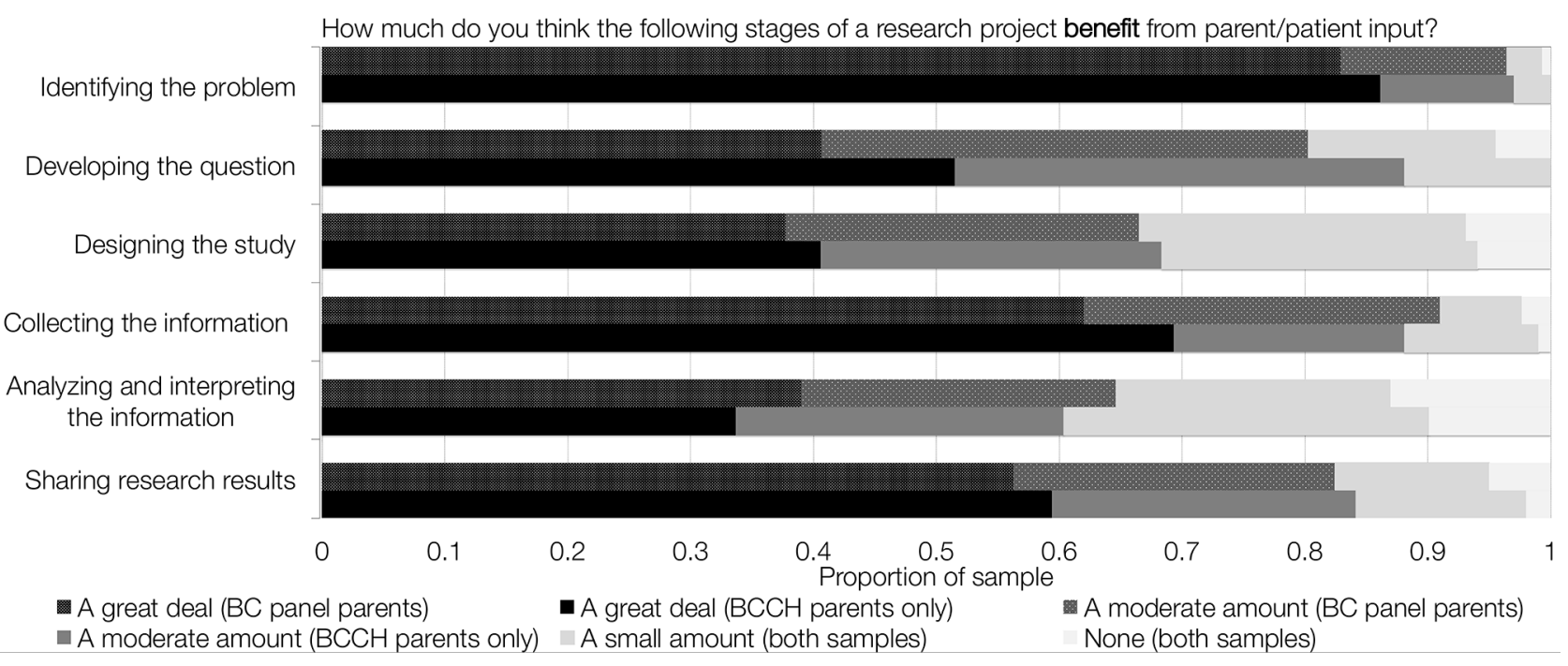

Figure 3 Benefits to the study. BC, British Columbia; $\mathrm{BCCH}, \mathrm{BC}$ Children's Hospital. 
How much would the following possible concerns be a barrier to you being a member of the research team?

The research study is too far away

Time commitment required (number of hours or extra hospital visits)

Having to drive to the hospital to participate in the study

Concern about my child's privacy

Don't think my children will want to participate

A research study that addresses an issue that's not important to me

The research study commitment is too long (takes place over multiple weeks/months)

Concern about the accuracy of the results

Concern about the importance of, or need for the research

Working with a research team who I'm not familiar with
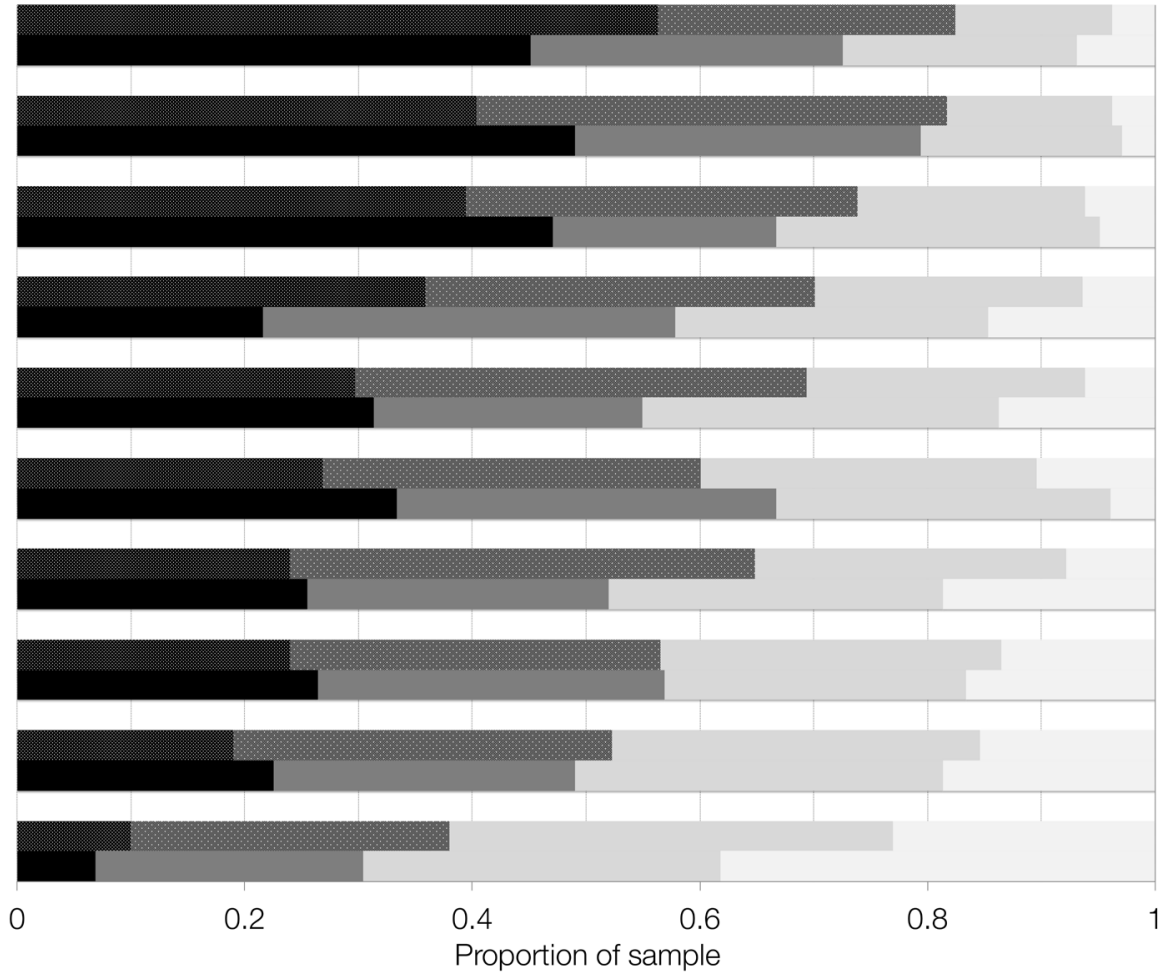

- A great deal (BC panel parents)

- A great deal (BCCH parents only)

A moderate amount (BC panel parents)

- A moderate amount (BCCH parents only)

A small amount (both samples)

None (both samples)

Figure 4 Barriers. BC, British Columbia; $\mathrm{BCCH}, \mathrm{BC}$ Children's Hospital.

Privacy, ethics and scientific research literacy

Parents expressed concerns about privacy when sharing personal information on behalf of their children online. Parents understood the trade-off between the amount of personal information they share on the platform and the relevance of the communications they would receive, but had concerns about how the information they shared would be protected. One parent said about disclosing their child's confidential information, 'I would need to ensure that I am making the right decision for my child, as [I'm] speaking on behalf of them'. Parents told us that they would be most comfortable with a staged, customizable enrolment

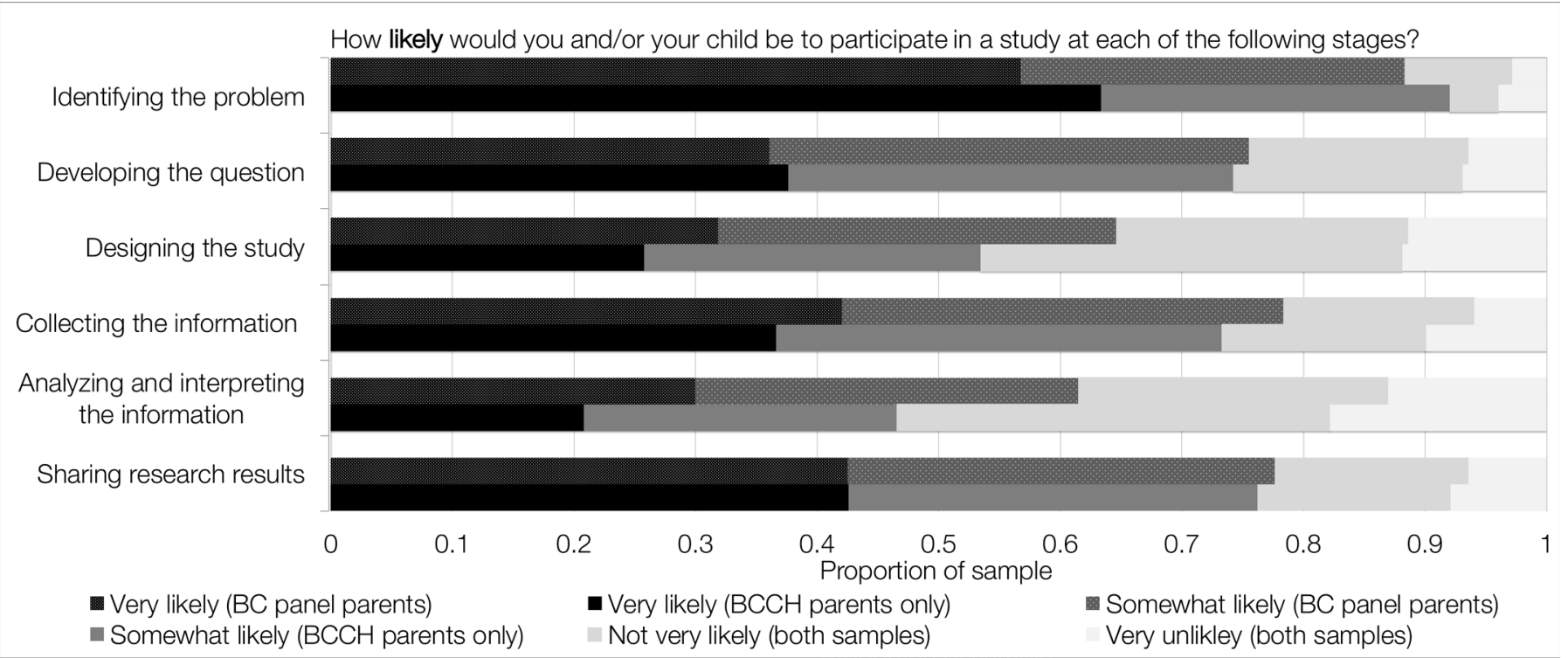

Figure 5 Likelihood of participating. BC, British Columbia; BCCH, BC Children's Hospital. 


\section{Identify the problem}

- 'Allows you to feel like their personal needs are being met'

- 'Ifresearchers aren't parents the how would they know about the problem?'

- 'If enough people come forwards with an issue then they can impact change'

Develop the question

- 'They [the questions] are the crux of the outcome'

- 'Your own lens and experience will influence the types of questions and studies that you do'

- 'There's value in developing the question, because then you can direct where things are going...'

\section{Design the study}

- 'It's the only stage of research where I can put my personal case'

- 'It's important that a study is laid out in layman's terms'

- 'I would prefer to design, because then you have the power to come up with ideas to influence and examine the topic'

- 'There's nothing worse than getting to the end of a survey and not having been able to get your point across'

Collect the information

- 'Collecting the information is important because it is a starting point [in research]'

- 'If it is a condition that your child is experiencing, then it is interesting to actually see what experiences others are having

- '[Collecting information is] perhaps one of the quickest and most gratifying way to feel like you are doing a part in research and making advancements'

Analyze \& interpret the information

- 'I'm unsure I'm qualified to analyze the information...'

- 'Allows people to express what they think it [data] means'

- 'Personal biases may affect research...'

- '[lt] would be good to see the results and see if there are any options'

- 'It takes time (...) probably not interested'

Share the results

- 'Sharing is important (...) and being 'in the know'"

- 'I cannot imagine particiapting in a study without being interested in the results'

- 'You get the word out there so you can help build and snowball the idea/findings and help more people that way'

Figure 6 Select parent quotes.

process, so that they would have control over the level of personal information that they share. Further discussion revealed that this group had little understanding of privacy laws and how those laws apply to the collection of personal information in BC and in Canada, as well as of the ethical standards to which health researchers and care providers are held accountable. For example, parents were concerned that information about their child would become part of a permanent record, which might then be shared with a third party for a purpose entirely unrelated to child health research.

\section{DISCUSSION}

The practice of involving patients as partners in research is supported by evidence of positive impact. ${ }^{317-19}$ A 2012 systematic review found that patient involvement at all stages of the research process resulted in identifying highly relevant research topics, pragmatic criticism of research protocols and more efficient participant recruitment. ${ }^{3}$ Patient involvement was also found to improve the capacity of the research team to identify important cultural issues and patient-reported outcome or experience measures, as well as to generate richer interview data and effectively disseminate research results with the assistance of peer advocates. ${ }^{3}$ These findings, combined with parent feedback in the present study, highlight an important opportunity for child health researchers to enhance the relevance and impact of their work by engaging with the population it is meant to serve.

Regardless of their previous access to care at BCCH, parents from across BC indicated that they would support and participate in a platform designed to catalyse patient-oriented research and improve child health in BC. Importantly, some parents expressed interest in a 
platform that transcends a single health condition or clinic and would, therefore, serve the paediatric population as a whole-including healthy children and their families. Therefore, our vision of Child-Sized KT as a holistic and inclusive, rather than segmented and targeted, platform based at BCCH is strongly supported by the feedback from parents. Results of the survey and focus groups indicated that trust in the BCCH brand is high among parents, yet they still had concerns about research ethics and privacy, particularly in an online environment, which would need to be addressed and built into the platform.

The present study provides a unique insight into the preferred mechanisms of patient engagement for parents on behalf of their children, as well as the facilitators and barriers to engagement. Finding time to engage in research was a key barrier identified by parents, which naturally led to a discussion of the need to incorporate mobile technology and provide a customisable interactive experience. Parents wanted to be able to engage with the platform on their own time and some wanted to view all opportunities for research participation. We heard from these parents that they-and their children-have many valuable experiences that are unrelated to their child's disease, and therefore potentially useful across many different research applications. An online platform could support their desire for flexibility, as all opportunities would be available to be reviewed and, depending on the needs of the specific project, accessed for participation at the family's convenience.

While we found no peer-reviewed literature regarding online patient engagement in child health research, acceptability and uptake of online portals for adolescent health management have been discussed in a quality improvement context. Studies in the USA and the Netherlands assessed parent and adolescent use of online portals designed to augment standard care. ${ }^{20} 21$ One portal permitted adolescents to engage in secure messaging with their care team, as well as participate in chats with their peers, while another was used by parents and adolescents to manage appointments, view lab results and medications. ${ }^{20} 21$ The authors described high levels of engagement with the portal among parents and adolescents, increased satisfaction with their care, as well as improvements in communication with their care teams. ${ }^{20}{ }^{21}$ While these studies were not focused on patient engagement in research, the acceptance, usage and appreciation of the portals demonstrated by the paediatric patient population provide support for an online component of ChildSized KT.

Despite the preference for online engagement expressed by parents in the current study, focus group participants had many ethical concerns and misconceptions related to sharing personal information for research purposes. The discussion about the nature of their concerns suggested that 'research literacy' education for parents and transparency around data governance ${ }^{22}$ will be vital to building trust in the online component of the proposed platform. Previous research has shown that educating patients can facilitate more meaningful participation in an advisory role by strengthening knowledge and debunking myths about how research is used to improve healthcare. ${ }^{23-25}$ Training to enhance understanding and to support BC patients in becoming partners in research is currently only available via in-person workshops through the multipartner organisation in BC enacting the goals of the CIHR SPOR initiative. ${ }^{26}$ Flexible, engaging, low-barrier online education that is tailored to the paediatric population is limited in Canada and represents a key gap that can be addressed by the Child-Sized KT platform in order to satisfy the concerns of $\mathrm{BC}$ parents.

Concerns about privacy did not dampen parents' enthusiasm for the opportunity to contribute more broadly to child health research in BC. The demand for patient-oriented research is driving innovative collaborations in Canada through the CIHR SPOR and globally. A powerful example in the USA is T1D Exchange (https:// t1dexchange.org) and the corresponding online patient community, Glu (https://myglu.org). T1D Exchange and Glu are a collaborative research community focused on patient-oriented type 1 diabetes research. Glu allows researchers to access data, crowd-source meaningful research questions and share research results. Patients can receive social support from peers, learn more about diabetes care and the latest research findings, as well as participate in studies. The bidirectional model has allowed for accelerated proliferation of research and translation of findings into practice. While Glu is limited to a single disease condition, the concept of bidirectional exchange is our inspiration for Child-Sized KT.

A strength of our study was the explanatory sequential mixed methods design, which allowed for rich data to be generated via qualitative exploration of themes emerging from quantitative data; however, the sample of parents from $\mathrm{BCCH}$ was confined to a single clinic because of limited resources and timelines for this study. Additionally, the sample of focus group participants was limited by budgetary constraints, and may not have been sufficient to achieve data saturation; however, despite being limited by resources to only two focus groups, similar themes emerged from both. While parents were not involved in the design of the present study, parents will be engaged in conducting future consultations that will include more clinics at the hospital, as well as youth and child perspectives, as iterative development of the Child-Sized KT prototype continues. ${ }^{8}$

\section{CONCLUSION}

By uniquely engaging the paediatric population, ChildSized KT will begin to fill the national and international need for KT specific to young persons, and accelerate progress to achieving the vision of patients as active partners in health research. As many children's engagement would be facilitated through their parents, this study provided insight into the needs and concerns of parents when considering their role as partners in child health 
research. Next steps will refine a concept of Child-Sized KT that includes an online component by seeking feedback from children and youth, and stakeholder populations with specific health concerns.

\section{Author affiliations}

${ }^{1} \mathrm{BC}$ Injury Research and Prevention Unit, Vancouver, British Columbia, Canada ${ }^{2}$ Department of Pediatrics, Faculty of Medicine, University of British Columbia, Vancouver, British Columbia, Canada

${ }^{3} \mathrm{BC}$ Children's Hospital Research Institute, Vancouver, British Columbia, Canada ${ }^{4}$ School of Population and Public Health, University of British Columbia, Vancouver, British Columbia, Canada

${ }^{5} \mathrm{BC}$ Children's Hospital, Vancouver, British Columbia, Canada

${ }^{6}$ Psychiatry, University of British Columbia, Vancouver, British Columbia, Canada

${ }^{7}$ Sunny Hill Health Centre for Children, Vancouver, British Columbia, Canada

Contributors JS, IP, MB, LT, LM, JWTM, AB, DM, RB, SG and SA designed the survey and focus group guides, contributed to the analysis and interpretation of the data, and reviewed and revised the manuscript. SA conceptualised and designed the study, coordinated and supervised data collection, and critically reviewed the manuscript for important intellectual content. JS drafted the initial manuscript, and coordinated and supervised data collection. LT, IP, JWTM and MB conceptualised and designed the study. All authors approved the final manuscript as submitted and agree to be accountable for all aspects of the work.

Funding This study was supported by the Canadian Institutes of Health Research (CIHR) Patient-Oriented Research Collaboration Grants, grant \#PEG-145205, and the BC Children's Hospital Research Institute Evidence to Innovation Theme.

Competing interests None declared.

Patient consent for publication Not required.

Ethics approval This study was reviewed and approved by the University of British Columbia Children's and Women's Hospital Research Ethics Board (cert\# H16-01342).

Provenance and peer review Not commissioned; externally peer reviewed.

Data sharing statement № additional data are available.

Open access This is an open access article distributed in accordance with the Creative Commons Attribution Non Commercial (CC BY-NC 4.0) license, which permits others to distribute, remix, adapt, build upon this work non-commercially, and license their derivative works on different terms, provided the original work is properly cited, appropriate credit is given, any changes made indicated, and the use is non-commercial. See: http://creativecommons.org/licenses/by-nc/4.0/.

\section{REFERENCES}

1. Nass P, Levine S, Yancy C. Methods for involving patients in topic generation for patient-centered comparative effectiveness research: an international perspective. Washington, DC, 2012.

2. Hamilton CB, Hoens AM, Backman CL, et al. An empirically based conceptual framework for fostering meaningful patient engagement in research. Health Expect 2018;21:396-406.

3. Brett J, Staniszewska S, Mockford C, et al. Mapping the impact of patient and public involvement on health and social care research: a systematic review. Health Expect 2014;17:637-50.
4. Shen S, Doyle-Thomas KAR, Beesley L, et al. How and why should we engage parents as co-researchers in health research? A scoping review of current practices. Health Expect 2017;20:543-54.

5. Canadian Institutes of Health Research. Strategy for Patient-Oriented Research.

6. Crandall WV, Margolis PA, Kappelman MD, et al. Improved outcomes in a quality improvement collaborative for pediatric inflammatory bowel disease. Pediatrics 2012;129:e1030-e1041.

7. David JG, Jofriet A, Seid M, et al. "A Guide to Gutsy Living": Patient-Driven Development of a Pediatric Ostomy Toolkit. Pediatrics 2018;141:e20172789.

8. Bradbury K, Morton K, Band R, et al. Using the Person-Based Approach to optimise a digital intervention for the management of hypertension. PLoS One 2018;13:e0196868.

9. Ivankova NV, Creswell JW, Stick SL. Using mixed-methods sequential explanatory design: from theory to practice. Field methods 2006;18:3-20.

10. Creswell J, Clark P V. Designing and conducting mixed methods research. Thousand Oaks: Sage, 2007.

11. Wolff B, Knodel J, Sittitrai W. Focus groups and surveys as complementary research methods. Morgan D, ed. Successful focus groups: advancing the state of the art. London: Sage, 1993:118-36.

12. Saint-Germain MA, Bassford TL, Montano G. Surveys and focus groups in health research with older hispanic women. Qual Health Res 1993;3:341-67.

13. Patton M. Qualitative Research and Evaluation Methods. Thousand Oaks: Sage, 2002.

14. Hsieh HF, Shannon SE. Three approaches to qualitative content analysis. Qual Health Res 2005;15:1277-88.

15. Government of British Columbia. Regional health authorities. https:// www2.gov.bc.ca/gov/content/health/about-bc-s-health-care-system/ partners/health-authorities/regional-health-authorities (Accessed 20 Jun 2018).

16. Office of the Auditor General of British Columbia. Health authority: overview. http://www.bcauditor.com/online/pubs/775/782 (Accessed 20 Jun 2018).

17. Domecq JP, Prutsky G, Elraiyah T, et al. Patient engagement in research: a systematic review. BMC Health Serv Res 2014;14:1-9.

18. Brett J, Staniszewska S, Mockford C, et al. A systematic review of the impact of patient and public involvement on service users, researchers and communities. Patient 2014;7:387-95.

19. Concannon TW, Fuster M, Saunders T, et al. A systematic review of stakeholder engagement in comparative effectiveness and patientcentered outcomes research. J Gen Intern Med 2014;29:1692-701.

20. Boogerd EA, Noordam C, Kremer JA, et al. Teaming up: feasibility of an online treatment environment for adolescents with type 1 diabetes. Pediatr Diabetes 2014;15:394-402.

21. Thompson LA, Martinko T, Budd $P$, et al. Meaningful use of a confidential adolescent patient portal. $J$ Adolesc Health 2016;58:134-40.

22. Longstaff $\mathrm{H}$, Khramova V, Portales-Casamar E, et al. Sharing with more caring: coordinating and improving the ethical governance of data and biomaterials obtained from children. PLoS One 2015;10:e0130527-12.

23. Coulter A, Ellins J. Effectiveness of strategies for informing, educating, and involving patients. BMJ 2007;335:24-7.

24. Shippee ND, Domecq Garces JP, Prutsky Lopez GJ, et al. Patient and service user engagement in research: a systematic review and synthesized framework. Health Expect 2015;18:1151-66.

25. Harrison JD, Anderson WG, Fagan M, et al. Patient and Family Advisory Councils (PFACs): identifying challenges and solutions to support engagement in research. Patient 2018;11:413-23.

26. SUPPORT Unit BC. Introductory workshops to patient-oriented research. http://bcsupportunit.ca/foundations-of-por/ (Accessed July $3,2018)$. 